\title{
Finite Element Analysis of Axial Fan Blade with Different Chord Lengths
}

\author{
Ali Zare ${ }^{1 *}$, Kannan M. Munisamy², Ali Najafzadeh³, Behzad Shahizare4, \\ Ahmad Ahmadi ${ }^{5}$ and Ahmed Ali Jaafari ${ }^{6}$ \\ Department of Mechanical Engineering, Universiti Tenaga Nasional, Kajang, Malaysia; \\ ali_z4688@yahoo.com¹, kannan@uniten.edu.my², alinajafzade1@gmail.com³, \\ shahizare@gmail.com4, mec.ahmadahmadi@yahoo.com5,ahmed-jaafary@hotmail.com
}

\begin{abstract}
Nowadays, improving energy efficient systems is one of the most controversial and significant global focuses. However, this trend in the field of engineering concentrates on the optimization of the existing technologies more than implementing new ones. Meanwhile, fans are one of the potent devices to be more efficient. Improvement in fan efficiency can be achieved by reducing material that is used in the fan blades. Due to this, decreasing the airfoil chord length to optimum value, leads to a decline in the amount of used materials in the blade design and manufacturing. In fan designing, Factor of safety should be considered. This factor changes by varying the chord length of the airfoil. However, this paper attempts to analyze the factor of safety in an axial fan blade with different chord lengths by use of finite element method. Due to this, axial fan blade with NACA5514 airfoil that is made by Aluminum 6061-T91 will be analyzed to find the correlation between the factor of safety and chord length in various pressure loads. The load values are determined by the experimental test.
\end{abstract}

Keywords: Axial Fan Blade, Finite Element Method, Chord Length, Factor of Safety, Stress Analysis, NACA Airfoil.

\section{Introduction}

A revolution in the $19^{\text {th }}$ century introduced a belt-driven fan in which wooden or metal blades were attached to the shaft. One of the first mechanical fans was built in 1832 and it was tested in coal mines. Further, developed fans have been utilized in diverse fields based on their applications [6]. These developments have been applied in various parts of the fan such as blades within which the twist angle and the shape of the cross section are of primary importance.

An airfoil is a streamline shape of cross section. The shape of the airfoil plays a very crucial role in the performance of its applications. It can reduce the flow turbulence and increase efficiency of the application. Airfoil cross section can be utilized in various areas such as a fan blade, airplane wing, and turbine.
As it is illustrated in Figure 1, the distance between blunt leading edge (LE) and trailing edge (TE) is called chord $(\mathrm{C})$, and the angle between the chord and the relative air velocity is called the angle of attack $(\alpha)$ [3].

National Advisory Committee for Aeronautics (NACA) is the most famous one in developing airfoil shapes of airplane wings, fans, and turbine blades since 1930. The "NACA" followed by four digits is called NACA 4_digit series. Each digit represents a specific characteristic of the airfoil. The first digit defines the maximum camber in hundredth of airfoil length. The second one specifies the distance of maximum camber of the airfoil from the leading edge in tens of chord length. The last two digits indicate maximum thickness of the airfoil in a hundredth of the chord length $[2,9]$.

Nowadays axial flow fans are mainly utilized for cooling and ventilation purposes. In order to have a more efficient

* Corresponding author:

Ali Zare (ali_z4688@yahoo.com) 


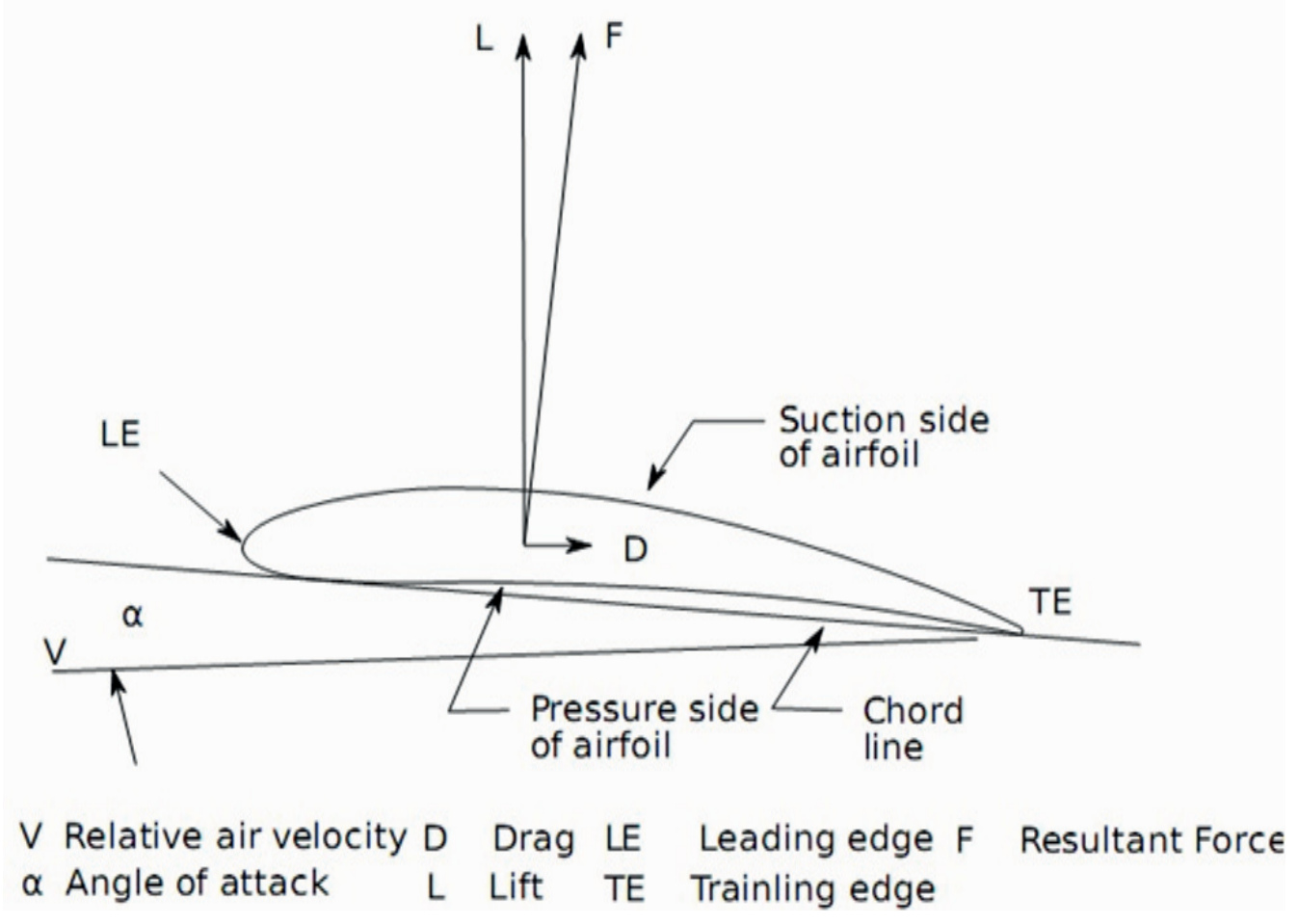

Figure 1. Airfoil shape of cross section.

Source: Adopted from Fan Handbook: selection, application, and design [3].

cooling and ventilation applications, the fan structure and its performance under certain conditions are very critical. Due to this, reducing the weight of the blade by decreasing the chord length is recommendable. This reduction may cause a failure in the blade; therefore, it must be controlled by the factor of safety (FOS). FOS can be achieved by the maximum of Von Mises stress in whole the blade. Changing the chord length must be done in a way that the series of airfoil keeps unchanged and remains NACA5514.

A plethora of scholarly research has been conducted in the area of designing the axial fan blade. Furthermore, several research has been done to optimize the chord lengths by utilizing various evolutionary optimizing techniques. Some works that form the background for this research are as follows:

In 1980, the dynamic stress analysis of rotating twisted and tapered blades were studied. The FEM was utilized to calculate the deformations and stresses. Three-dimensional, twenty-node isoparametric elements were utilized for the analysis. Further analysis was done on different airfoil chord lengths of the blades. The numerical results were verified by experimental results [13].

In 1994, a matrix was developed in order to determine the effects of airfoil thickness and maximum lift. Then, the airfoils were designed and analyzed. Later, the theoretical analysis of accepted airfoils verified by the experimental results in the Pennsylvania State University low-speed, low-turbulence wind tunnel [4].

In 2000, an efficient implementation of the Blade Element and Momentum theory was utilized to optimize the chord length due to its reasonable and accurate estimation of performance. As the BEM theory has presented an acceptable accuracy with regard to time cost, it can be considered as a suitable theory for blade geometry optimization $[5,11]$.

In 2005, the effects of airfoil thickness and maximum lift coefficient on roughness sensitivity was studied. The study defined that the effects of the roughness sensitivity on the maximum lift coefficient increase by increasing the thickness of the airfoil. The experimental and theoretical results showed a good agreement [15].

In 2006, a method by the use of genetic algorithms was presented to obtain the optimal chord length of the blade in a wind turbine. This method neglected the assumptions about optimal attack angle related to the coefficient of lift to drag ratio [12].

In 2011, the blade thickness effects on the performance of an axial fan was studied. In that study, two fan blades 
with different thicknesses were examined. The first blade was very thin while the second blade was much thicker. The fan performances were examined in a test bench designed according to the ISO-5801 standard. In result, the thin blade fan had a higher efficiency than the thick blade. In comparison to the thin blade fan, the thick blade one has a higher flow rate range and lower total level of fluctuations [14].

In 2012, a study has been conducted on estimating the optimal shape of an axial fan blade, such as chord length and angle of twist. At first, numerical calculations were implemented to design and analyze the optimal shapes of fan blades with NACA 4-digit series airfoil. The experimental test validated the accuracy of its estimations [8]. In addition, in the same year, the similar optimization of the chord length on the axial fan blade and wind turbine blade was done $[1,10]$.

Fans have several applications in modern life; therefore, saving energy and material play crucial roles in their design and manufacturing. Reaching the global goal of saving energy and material necessitates a close analysis of various variables in fans. Meanwhile, reducing airfoil chord length leads to decrease in the amount of material that is used in the blade manufacturing. However, FOS is a very important criterion in designing and manufacturing of the fan. The objective of this study is analyzing the FOS in different chord lengths to find their correlation.

\section{Materials and Methods}

In this study, an axial fan blade with the following specifications will be examined. Model Number of the fan is 1250-350-12 (30deg) with the Impeller Diameter of 1245 $\mathrm{mm}$. Inlet and Outlet Areas of the fan are $1.2272 \mathrm{~m}^{2}$ and $1.2272 \mathrm{~m}^{2}$. The fan blade length is $446.5 \mathrm{~mm}$ with the cross section of NACA5514. The primary blade chord length before variation is $130 \mathrm{~mm}$ with the twist angle of $5^{\circ}$.

The blade is made of Aluminum 6061-T91 with the Modulus of Elasticity of $69.0 \mathrm{GPa}$, density of $2.7 \mathrm{~g} / \mathrm{cc}$, Poisson's Ratio of 0.330, and Tensile Strength of $395 \mathrm{MPa}$. The pressure load is applied to the lower surface of the blade.

\subsection{Experimental Results}

Different pressure load values were applied to the blades. These values achieved from experimental tests, which were done by GT-Gulf (M) Sdn Bhd company under AMCA standards on January 10, 2011. The data were achieved from experimental results of Test No. 27353-A2, which was named as CONTRACT TESTING - MODEL No. TFA 1250-350-12. The chord length of the blade in this test was $130 \mathrm{~mm}$. The fan was tested in a wind tunnel. Based on the experimental data, the pressure load values were measured in different regions; from free delivery to stall. The pressure load values vary from $0 \mathrm{kPa}$ to $800 \mathrm{kPa}$. This pressure applies load on the lower surface of the blade, which can be considered as a surface pressure.

\subsection{Finite Element Method}

The finite element methods (FEM) are techniques utilized for approximating differential equations to continuous algebraic equations by a finite number of variables [7]. This method is one of the most practical ways for analyzing structures with a large number of degrees of freedom. To get a more accurate result from FEM, it is recommended to use some software in order to carry out the numerical computation part. In addition, saving time is another factor which motivates specialists to use software instead of solving problems manually [17]. Various FEM based software such as ABAQU are utilized to solve engineering problems. In this study, ABAQUS software is used to analyze Von Mises stress in the axial fan blade.

\subsection{Mesh Convergence Study}

A mesh convergence study was done to choose the optimum mesh number from the computational accuracy point of view. Meanwhile, Von Mises stress was computed for different types of meshing. In these types of finite element analysis, Three-Dimensional with HEX type of element are more suitable than rectangular or triangular flat elements [16].

In order to get better result in different analysis with ABAQUS software, mesh convergence study was done in the sample simulations. As it is shown in Figure 2., by increasing the number of elements, Von Mises stress goes up sharply and then approximately remains steady. The mesh convergence study was started with 88 elements that increase until 356005 elements. In the first test, Von Mises stress is $1.15653 \mathrm{MPa}$, which goes up until 1.65723 MPa in the last test at 356005 elements. As it is shown, in 106148 elements, Von Mises stress stops its sharp increase at $1.63685 \mathrm{MPa}$ and keeps its very slight rise until the last point. As it is shown in the Figure 2., the point with 106148 elements is a proper point to be utilized in all simulations.

Figure 3. demonstrates a meshed blade with 106148 elements. 


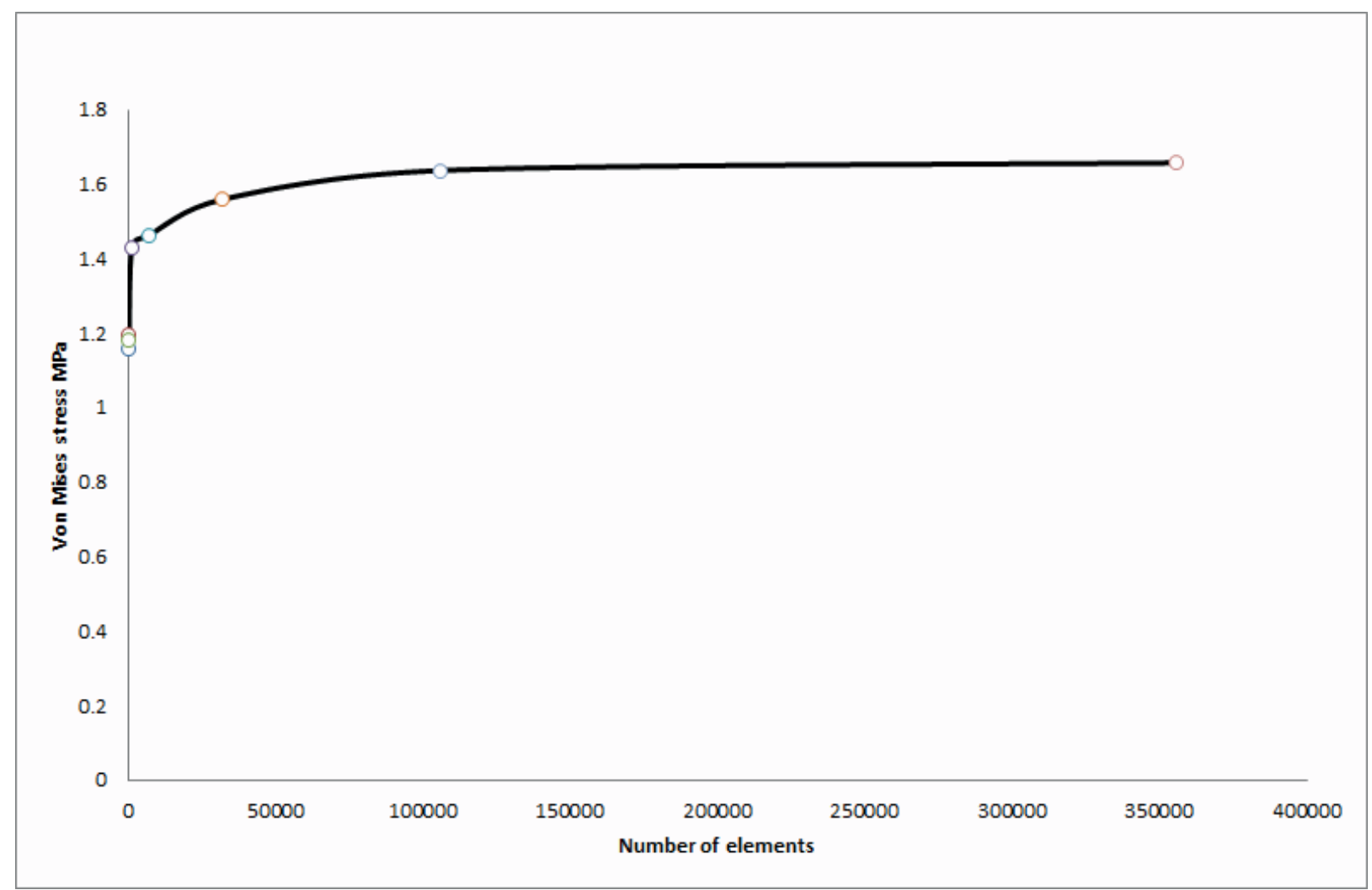

Figure 2. Trend line of mesh convergence study.

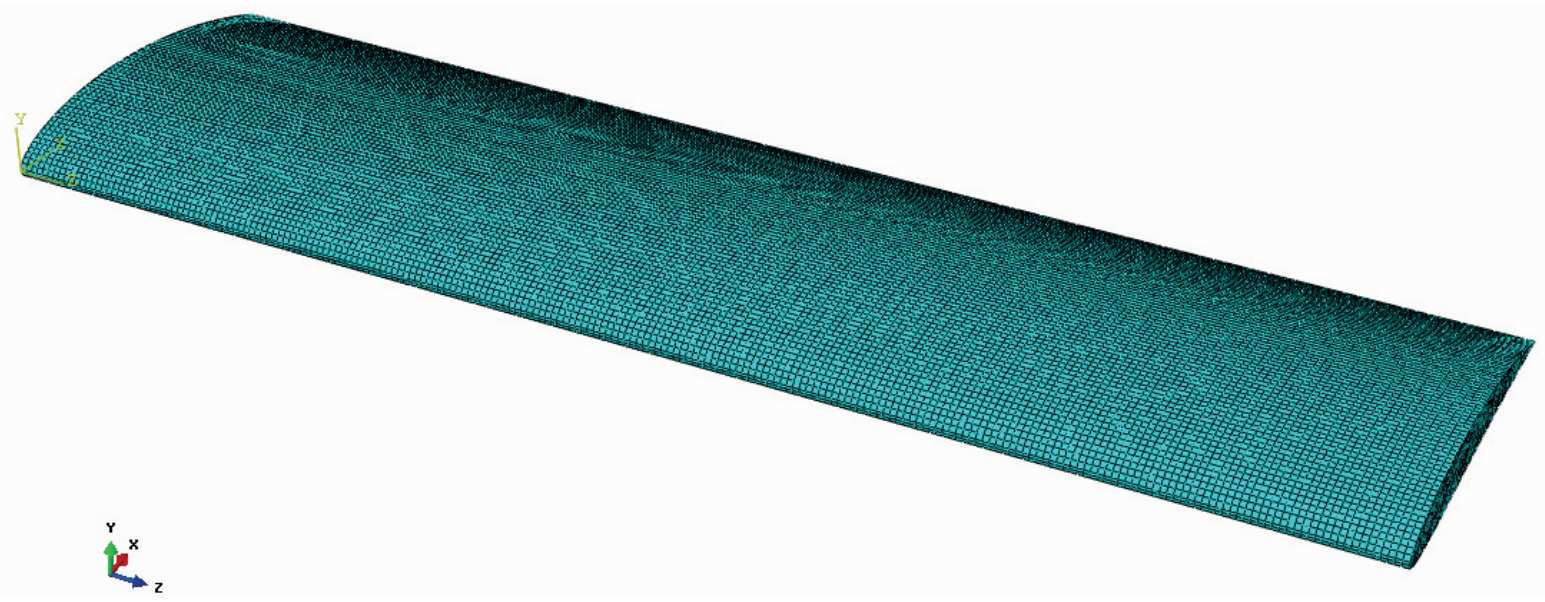

Figure 3. Meshed blade with 106148 elements.

\section{Result and Discussion}

Changing the chord length leads to a change in the factor of safety. The first chord length based on the experimental test is $130 \mathrm{~mm}$. This study attempts to decrease the chord length to find its correlation with the factor of safety. In this study, the minimum of the chord length based on the fan design is considered $70 \mathrm{~mm}$. Due to this; the simulations were done on various chord lengths that vary from $130 \mathrm{~mm}$ to $70 \mathrm{~mm}$.

Figure 4. presents NACA5514 airfoil with different chord lengths. 


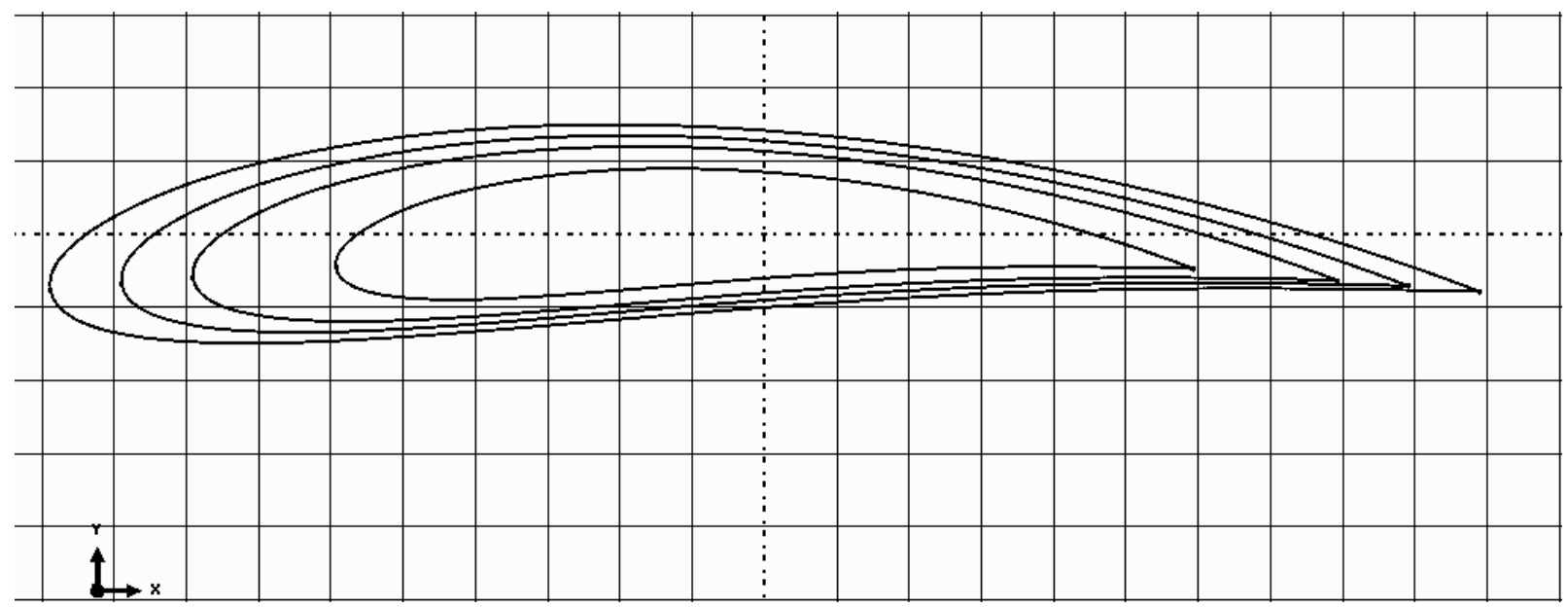

Figure 4. Various chord lengths of NACA5514.

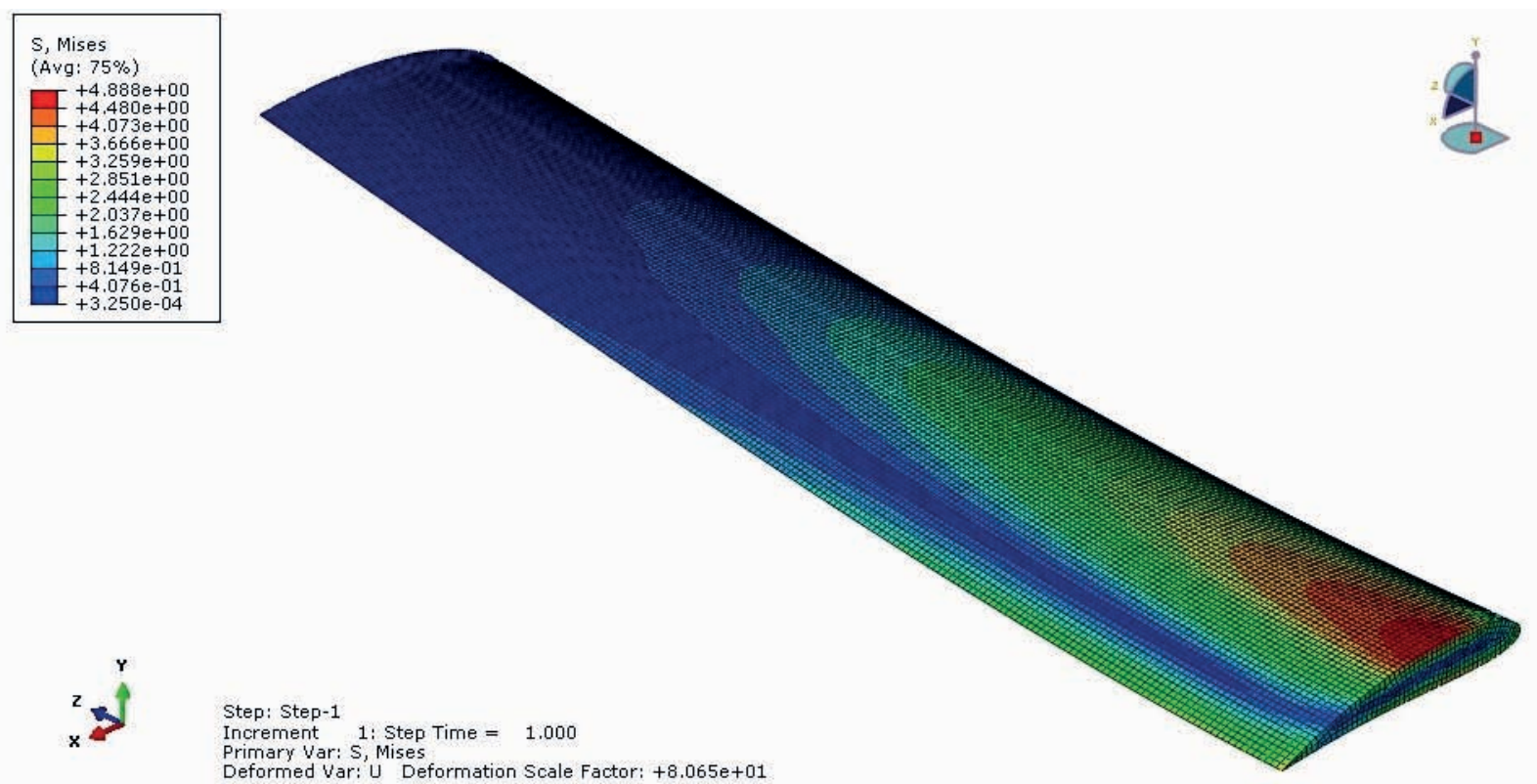

Figure 5. Von Mises stress (MPa), $\alpha=5^{\circ}$, deformed shape under $500 \mathrm{kPa}$, chord length of $100 \mathrm{~mm}$.

The Von Mises stress is a very important value in the result of ABAQUS software that helps to find the factor of safety. The Figure 5. shows Von Mises stress in the axial fan blade under $500 \mathrm{kPa}$ pressure load on lower surface with the twist angle of $5^{\circ}$, and chord length of $100 \mathrm{~mm}$. The maximum of Von Mises stress is $4.88 \mathrm{MPa}$.

The graph in Figure 6. demonstrates that by increasing the chord length, Von Mises stress decreases exponentially. The highest values of Von Mises stress relate to $800 \mathrm{kPa}$ series, and the lowest ones relate to
$100 \mathrm{kPa}$. The maximum of Von Mises stress is 8.768 MPa under $800 \mathrm{kPa}$ and $70 \mathrm{~mm}$ of chord size and the minimum is $0.3295 \mathrm{MPa}$ under $100 \mathrm{kPa}$ and $130 \mathrm{~mm}$ of chord length.

The Figure 7. shows that by increasing the chord length, FOS rises up. In addition, FOS falls by ascending the pressure load. The highest value of FOS is 1198.6151 that is related to $100 \mathrm{kPa}$ with the highest chord length. The minimum of the FOS is 45.05 that contributes to $800 \mathrm{kPa}$ with $70 \mathrm{~mm}$ of the chord length. 


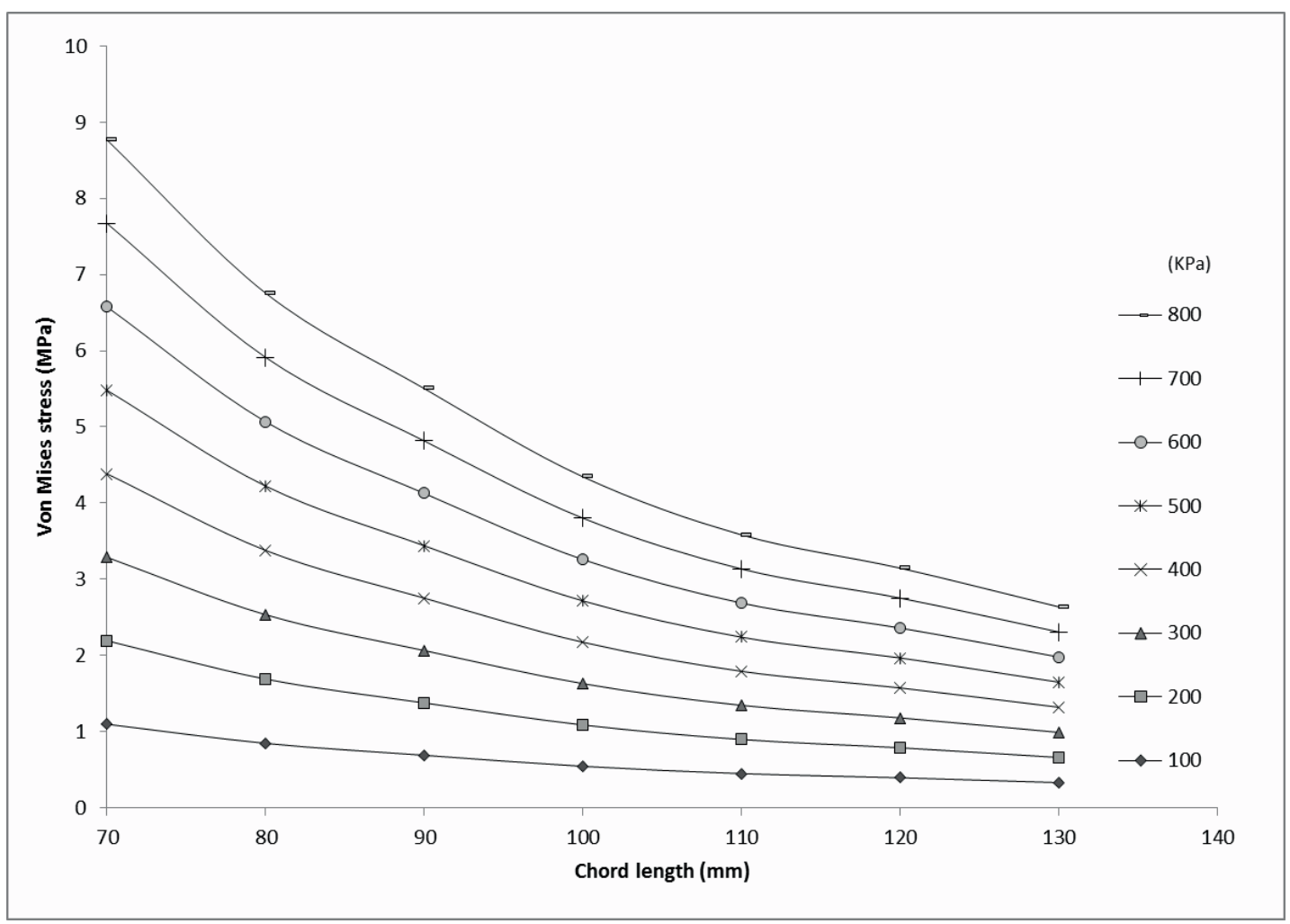

Figure 6. Von Mises stress $(\mathrm{MPa})$ vs. chord length $(\mathrm{mm})$ in various pressure loads, $\alpha=5^{\circ}$.

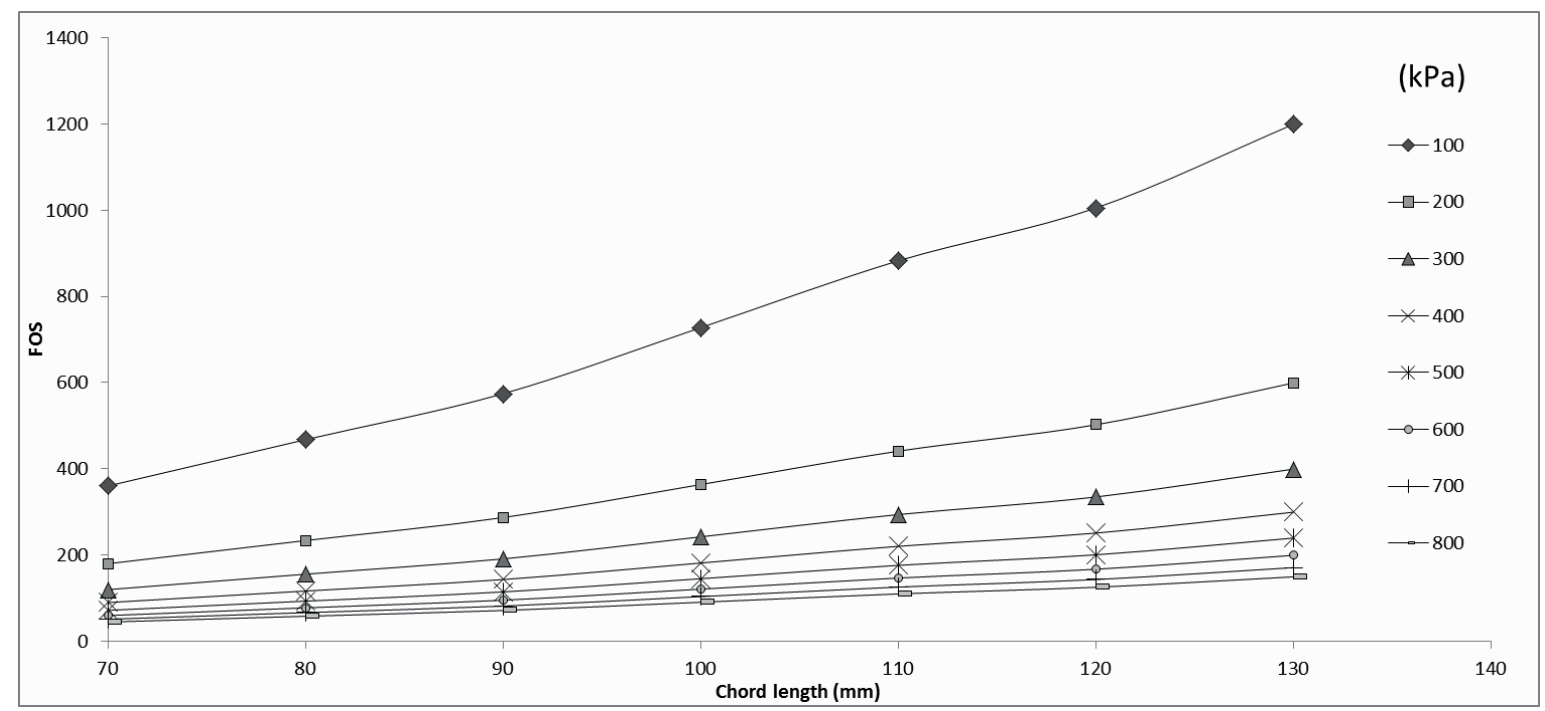

Figure 7. FOS vs. chord length $(\mathrm{mm})$ in various pressure loads $(\mathrm{kPa})$.

\section{Conclusion}

As the objective of this study was finding the correlation of the chord length and FOS in the NACA5514 airfoil fan blade, it examined the mentioned variables by the use of
FEM. The length of the utilized blade in this study was $446.5 \mathrm{~mm}$ that was made from Aluminum 6061-T9.

In order to complete this study, the basic concepts related to the axial fan field were elaborated. Furthermore, a close investigation of previous studies were done. Then, 
ABAQUS software was adopted to simulate the airfoil blade with different characteristics. The Pressure loads, which were achieved by experimental tests, were applied on the lower surface of the blade. They varied from $100 \mathrm{kPa}$ to $800 \mathrm{kPa}$. Finally, Von Mises stress was achieved from the simulation result. This value was utilized to find the factor of safety.

The analysis was done on the different chord length. The blade had a $5^{\circ}$ of twist angle. The simulation results shows that by increasing the pressure load in a constant chord length, Von Mises stress goes up while the factor of safety falls. By reducing the chord length of the blade, Von Mises stress ascents while the factor of safety descends.

The best factor of safety is at the minimum chord length of $70 \mathrm{~mm}$. This value can be considered as a proper chord length of the fan blade.

\section{Recommendation for Future Work}

Selecting the best chord length is confined with some other factors in the fluid flow field such as CFM, pressure, BHP. According to this, it is recommended to study these factors in the fluid flow field by CFD method to analyze the best performance of the fan. In addition, the material of the blade can be changed. In order to reduce the weight of the fan blade and increase the mechanical properties of the fan, composite materials such as FRP can be utilized. This goal can be obtained by finding the value of these factors and comparing them with the factor of safety to find the optimized geometry and th best material.

\section{Acknowledgement}

The author is grateful to Universiti Tenaga Nasional, MOHE, and GTG Industries Sdn. Bhd. for supporting this research.

\section{References}

1. Abdullah O I, and Schlattmann J (2012). Stress Analysis of Axial Flow Fan, Adv. Theor. Appl. Mech, vol 5(6), 263-275.

2. Anderson J D (2001). Fundamentals of aerodynamics,McGraw-Hill, New York, vol 2.
3. Bleier F P (1998). Fan Handbook: selection, application, and design, McGraw-Hill, New York.

4. Brophy C M (1994). Turbulence management and flow qualification of the Pennsylvania State University low-turbulence, low-speed, closed-circuit wind tunnel, Pennsylvania State University.

5. Burton T, Sharpe D et al. (2001). Wind energy handbook, Closed-loop Control: Issues and Objectives, $2^{\text {nd }}$ Edn., John Wiley \& Sons, Ltd., UK, 478.

6. Desai D J (2012). Optimization design of a low speed axial flow fan used for local ventilation in the mining industry, Lamar University, Beaumont.

7. Foroni F D, Filho L A et al. (2007). Blade design and forming for fans using finite elements, Innovative Algorithms and Techniques in Automation, Industrial Electronics and Telecommunications, 135-140.

8. Huang C H, and Gau C W (2012). An optimal design for axialflow fan blade: theoretical and experimental studies, Journal of mechanical science and technology, vol 26(2), 427-436.

9. Jacobs E N, Ward KE et al. (1933). The characteristics of 78 related airfoil sections from tests in the variable-density wind tunnel: US Government Printing Office.

10. Jeong J, Park K et al. (2012). Design optimization of a wind turbine blade to reduce the fluctuating unsteady aerodynamic load in turbulent wind, Journal of Mechanical Science and Technology, vol 26(3), 827-838.

11. Martin O L (2000). Hansen: Aerodynamics of Wind Turbines, Rotors, Loads and Structure: James \& James Ltd., London, 89.

12. Méndez J, and Greiner D (2006). Wind blade chord and twist angle optimization using genetic algorithms, Paper presented at the Fifth International Conference on Engineering Computational Technology, Las Palmas de Gran Canaria, Spain.

13. Ramamurti V, and Sreenivasamurthy S (1980). Dynamic stress analysis of rotating twisted and tapered blades, The Journal of Strain Analysis for Engineering Design, vol 15(3), 117-126.

14. Sarraf C, Nouri H et al. (2011). Experimental study of blade thickness effects on the overall and local performances of a Controlled Vortex Designed axial-flow fan, Experimental Thermal and Fluid Science, vol 35(4), 684-693.

15. Somers D M (2005). Effects of Airfoil Thickness and Maximum Lift Coefficient on Roughness Sensitivity, National Renewable Energy Laboratory, USA.

16. Zienkiewicz O C, and Taylor R L (2000). The Finite Element Method:SolidMechanics, $5^{\text {th }}$ Edn., Butterworth-Heinemann, vol 2.

17. Zienkiewicz O C, Taylor R L et al. (2005). The finite element method: its basis and fundamentals, $6^{\text {th }}$ Edn. ButterworthHeinemann, vol 1. 